Volume 2

\title{
Coronary Aorta Systolic and Diastolic Pressure Indices: Two Novel Indicators for Predicting Significant Coronary Stenosis -- A Validation Against Fractional Flow Reserve
}

\author{
Mirza Mujadil Ahmad \\ Khawaja Afzal Ammar \\ Mirza Nubair Ahmad \\ Arsalan Riaz \\ Fatima A. Husain \\ Syed Shahab Kazmi \\ Imran Husain \\ Anjan Gupta
}

Follow this and additional works at: https://aah.org/jpcrr

Part of the Cardiology Commons, Cardiovascular Diseases Commons, and the Cardiovascular System Commons

\section{Recommended Citation}

Ahmad M, Ammar K, Ahmad M, Riaz A, Husain FA, Kazmi S, Husain I, Gupta A. Coronary Aorta Systolic and Diastolic Pressure Indices: Two Novel Indicators for Predicting Significant Coronary Stenosis -- A Validation Against Fractional Flow Reserve. J Patient Cent Res Rev 2015;2:216-217. http://dx.doi.org/ 10.17294/2330-0698.1248

Published quarterly by Midwest-based health system Advocate Aurora Health and indexed in PubMed Central, the Journal of Patient-Centered Research and Reviews (JPCRR) is an open access, peer-reviewed medical journal focused on disseminating scholarly works devoted to improving patient-centered care practices, health outcomes, and the patient experience. 
to original diagnosis. Twelve women who developed a SCSE (cases) were matched to 44 women who did not (controls) at least 5 years after initial diagnosis. Archived tissues were stained for p16INK4a, Ki67 and COX-2 using "multiplex immunohistochemistry," enabling simultaneous interrogation of expression levels of the three biomarkers in a single tissue section.

Results: Our multiplex analysis revealed that expression levels of Ki-67, p16INK4a or COX-2, either in epithelial cells within the lesion or in stromal cells adjacent to the lesion, either individually or in combination, do not predict the development of a SCSE in women initially diagnosed with $\mathrm{ADH} / \mathrm{ALH}$ or UDH. However, this analysis identified double- or triple-positive cells in the vicinity of the lesions in some cases and controls.

Conclusion: Expression of Ki-67, p16INK4a and COX-2 is not predictive of a SCSE following initial diagnosis of ADH/ ALH or UDH. Further analysis is needed on a larger cohort after longer follow-up after initial diagnosis to confirm our findings and to investigate whether the presence of doubleor triple-positive cells (a signature predicted to correlate with poor outcome) is predictive of progression regardless of the expression status of the lesion.

\section{The Effect of Percutaneous Closure of Large Atrial Septal Defects on Right Ventricular Function in Adults}

Armaan Shaikh, Alejandro Lopez-Mas, Suhail Allaqaband, Bijoy K. Khandheria, Abraham Getenet, Matt M. Umland, Maharaj Singh, Tanvir Bajwa

Aurora Cardiovascular Services, Aurora Health Care; Department of Internal Medicine, Aurora Sinai Medical Center; Aurora Research Institute, Aurora Health Care

Background: Percutaneous closure of atrial septal defects has been shown to be a safe alternative to surgery. Despite this, past studies have largely been focused on either smallto medium-sized atrial septal defects or percutaneous closure in children and young adults.

Purpose: Our study sought to examine if right ventricular function and size improved after percutaneous closure of large atrial septal defects in the adult population.

Methods: Over a 5-year span, 25 patients underwent percutaneous closure of a secundum atrial septal defect with an occluder device. A retrospective examination was conducted for each patient, including both echocardiography and chart review for postdevice complications/symptoms.

Results: Average patient age was 44.4 years, and mean device size was $28 \mathrm{~mm}$ (range: 24-38 mm). Follow-up echocardiography (mean of 134 days) showed tricuspid annular plane systolic excursion was significantly improved (2.11 vs. 2.33; $\mathrm{P}=0.013$ ). There also was a significant reduction in right ventricular diastolic chamber size (31.0 vs. 35.4; $\mathrm{P}<0.01$ ). At 1 -year postprocedure follow-up, zero patients had experienced transient ischemic attack, stroke or device perforation/embolization.
Conclusion: Percutaneous closure of large secundum atrial septal defects in adults improves right ventricular function as well as right ventricular chamber size. Percutaneous closure of large atrial septal defects also is a safe, very low-risk procedure in terms of future adverse neurologic, embolic or perforation-related events.

\section{Coronary Aorta Systolic and Diastolic Pressure Indices: Two Novel Indicators for Predicting Significant Coronary Stenosis - A Validation Against Fractional Flow Reserve}

Mirza Mujadil Ahmad, Khawaja Afzal Ammar, Mirza Nubair Ahmad, Arsalan Riaz, Fatima A. Husain, Syed Shahab Kazmi, Imran Husain, Anjan Gupta

\section{Aurora Cardiovascular Services, Aurora Health Care}

Background: Since most of the coronary flow occurs in diastole, either mean $\mathrm{Pd} / \mathrm{Pa}$ or $\mathrm{iFR}$ has been used to measure the hemodynamic significance of a coronary stenosis. We have observed that a significant pressure gradient exists in coronary stenosis even in systole, which is contrary to general understanding but similar to ankle brachial index. Furthermore, prior studies have evaluated baseline $\mathrm{Pd} / \mathrm{Pa}$ (mean coronary artery/mean aorta pressure) ratio as well as iFR (instantaneous wave-free ratio obtained during entire period of diastole) to predict fractional flow reserve (FFR) $\leq$ 0.80 . We hypothesized a simple end-systolic and -diastolic pressure measurement in the coronary artery distal to stenosis may perform adequately to predict FFR, obviating a need to measure $\mathrm{Pd} / \mathrm{Pa}$ or $\mathrm{iFR}$.

Purpose: We sought to evaluate systolic and diastolic $\mathrm{Pd} /$ $\mathrm{Pa}$, and termed them coronary artery systolic pressure index (CASPI) and coronary artery diastolic pressure index (CADPI), respectively, against FFR $\leq 0.80$.

Methods: After retrospectively identifying 555 moderate stenotic lesions undergoing FFR measurement at a tertiary care center over a 4-year period, we procured original pressure tracings obtained during the cardiac catheterization and manually measured systolic and diastolic pressures in the aorta and in the coronary artery distal to the stenosis, before and after adenosine infusion. Utilizing FFR $\leq 0.80$, operating test characteristics of CASPI and CADPI were measured and compared to those of baseline $\mathrm{Pd} / \mathrm{Pa}$.

Results: In the 555 lesions, mean CASPI $(0.97 \pm 0.04)$ and CADPI $(0.95 \pm 0.08)$ were similar to baseline $\mathrm{Pd} / \mathrm{Pa}(0.95 \pm$ 0.05). CASPI correlated well with baseline $\mathrm{Pd} / \mathrm{Pa}$ (Spearman $\mathrm{r}=0.81 ; \mathrm{P}<0.0001)$. Similarly, CADPI was strongly correlated with baseline $\mathrm{Pd} / \mathrm{Pa}(0.86 ; \mathrm{P}<0.0001)$. The area under the receiver operating curve (AUC) was lower for CASPI and CADPI, as compared to baseline $\mathrm{Pd} / \mathrm{Pa}(0.80$ vs. 0.82 vs. 0.89 , respectively), for predicting the FFR $\leq 0.80$. For a CASPI $<$ 0.88 there were no false positives with $100 \%$ specificity, and for a CASPI $>1.02$, there were no false negatives with $100 \%$ sensitivity. Similarly, for a CADPI $<0.8$ there were no false positives with $100 \%$ specificity, and for CADPI $>1.16$ there were no false negatives with $100 \%$ sensitivity. 
Conclusion: These data demonstrate that contrary to the popular belief, significant systolic and diastolic pressure gradients distal to coronary stenosis exist with a reasonable but lower predictive power towards FFR $\leq 0.80$.

\section{Contemporary Usage of Intra-Arterial Catheter- Directed Thrombolytic (CDT) Power Pulse Spray With Rheolytic Thrombectomy in Failed CDT Alone for Acute Limb Ischemia}

Hani Hashim, M. Fuad Jan, Maharaj Singh, Suhail Allaqaband, Tanvir Bajwa, Anjan Gupta

Aurora Cardiovascular Services, Aurora Health Care; Aurora Research Institute, Aurora Health Care

Background: Acute lower limb ischemia (ALI) caused by arterial embolism, thrombosis of native vessels, and/ or grafts is a serious condition associated with substantial morbidity and mortality. Peripheral arterial thrombolysis utilizing catheter-directed thrombolytic (CDT) has become established as a useful option in the management of ALI. However, use and outcome of adjunctive power pulse spray with rheolytic thrombectomy (PPSRT) following unsuccessful CDT is underreported in the literature.

Purpose: To evaluate outcome of contemporary use of intraarterial CDT PPSRT as an adjunct to unsuccessful standard CDT for ALI.

Methods: We reviewed 78 consecutive patients (mean age $69 \pm$ 14.2 years, $48.8 \%$ female) who presented to Aurora St. Luke's Medical Center with less than 14 days of ALI from January 2004 to October 2014. All patients had percutaneous transluminal angioplasty procedures as a standard revascularization option for ALI. Data were collected from electronic medical records, and billing codes. Continuous variables were expressed as mean \pm standard deviation and range, and categorical variables as frequency count and percentage. Differences between the groups were analyzed with t-tests or analysis of variance and chi-square or Fisher's test.

Results: 48 patients (Group 1) underwent CDT alone with successful technical and clinical results, while 30 patients (Group 2) who had unsuccessful CDT results underwent adjunctive CDT with PPSRT. There was no statistical significance among both groups in regard to their baseline characteristics. In Group 1 and Group 2, respectively, limb salvage was $87.5 \%$ and $86.6 \%(\mathrm{P}=\mathrm{ns})$, amputation at 30 days $13 \%$ and $16 \%(\mathrm{P}=\mathrm{ns})$, embolectomy $16.67 \%$ and $20 \%(\mathrm{P}=\mathrm{ns})$, emergent bypass graft $8.3 \%$ and $13.33 \%(\mathrm{P}=\mathrm{ns})$, distal embolization $14.89 \%$ and $17.24 \%(\mathrm{P}=\mathrm{ns}), 30$-day compartmental syndrome $12.5 \%$ and $13.79 \%(\mathrm{P}=\mathrm{ns})$, death at 30 days $8.8 \%$ and $13.33 \%(\mathrm{P}=\mathrm{ns})$, and bleeding requiring blood transfusion $16 \%$ and $14 \%(\mathrm{P}=\mathrm{ns})$. Hemorrhagic stroke occurred in one patient of Group 1. Complete and partial analysis achieved in (Group 2) $73.4 \%$, length of hospitalization was $10.6 \pm 6.25$ days $(\mathrm{P}=\mathrm{ns})$.

Conclusion: Adding intra-arterial CDT power pulse spray with rheolytic thrombectomy to unsuccessful standard CDT as an adjunctive procedure is a powerful revascularization tool for lower extremity acute limb ischemia that achieves success in the vast majority of patients, is not associated with higher complications when compared to successful CDT alone, and obviates the need for emergent surgical revascularization.

\section{Additional Presentations}

The following citations reflect additional 2015 Aurora Scientific Day presentations, some of which have been published as abstracts or articles in scientific journals.

First Place Poster (tie): Ali Z, Greer DM, Shearer R, Alemu A, Jahangir A. Androgen suppression effects on heart failure and in patients with prostate cancer. $\mathrm{J} \mathrm{Am}$ Coll Cardiol. 2015;65(10S):A887.

Second Place Poster: Muluneh A, Nfor T, Bajwa T, Biru NY, Parmar HS, Greer DM, Belete HM. Evaluating MACE associated with temporary discontinuation of antiplatelets for acute GI bleeding in patients with coronary stents. Poster presented at Aurora Scientific Day, Milwaukee, WI, May 20, 2015.

Rieselbach Distinguished Paper \#2: Forgie MM, Greer DM, Kram JJF, Bernhard KA, Salvo NP, Siddiqui DS. A randomized control trial of Foley catheter placement for induction of labor: stylette versus no stylette. Orally presented at Aurora Scientific Day, Milwaukee, WI, May 20, 2015 .

Rieselbach Distinguished Paper \#3: Yousaf H, Ahmad MN, Ammar KA, Yusuf SH, Ellis MK. Operating test characteristics of respiratory exchange ratio as a noninvasive measure of anaerobic threshold. Circulation. 2013;128:A13761.

Rieselbach Distinguished Paper \#4: Ali Z, Greer DM, Shearer R, Gardezi AS, Chandel A, Jahangir A. Effects of testosterone supplement therapy on cardiovascular outcomes in men with low testosterone. $\mathrm{J} \mathrm{Am} \mathrm{Coll} \mathrm{Cardiol.}$ 2015;65(10S):A1346.

Shi Y, Cho C, Garlie L, Perez R, Shearer R, Sulemanjee $\mathrm{N}$, Zwicke D, Hastings T, Cheema O, Thohan V. Echocardiographic markers of implantable cardioverterdefibrillator therapy. J Am Coll Cardiol. 2015;65(10S):A913.

Honoris L, DeFranco A, Port S, Cho C, Li D, Nasir K, Kronmal R, Barr RG, Budoff M. Correlation of coronary artery calcium scoring on ungated computed tomography compared to gated cardiac computed tomography scans from the multi-ethnic study of atherosclerosis. $J$ Am Coll Cardiol. 2015;65(10S):A1063. 